\title{
Sixty years since vasopressin synthetic preparation followed by a nobel prize. Is it time to augment its use in cardiac surgery?
}

\section{Editorial}

The first complete synthetic preparation of vasopressin (AVP) was reported in 1954 from Du Vigneaud, Gash et al. ${ }^{1}$ which lead to the award of the Nobel Prize in Chemistry to Vincent du Vigneaud one year later "for his work on biochemically important sulphur compounds, especially for the first synthesis of a polypeptide hormone".

This hormone has been shown to have effects within minutes when administrated intravenously. AVP rapidly distributes from plasma into the extracellular fluid volume. It is metabolized by the liver and the kidneys, and a small proportion is eliminated with the urine. The plasma half-life is very short $(4-20 \mathrm{~min})$, resulting in the necessity of continuous infusion in order to maintain its effects. Vasopressin causes vasoconstriction in skin, skeletal muscle, and mesenteric blood vessels mediated via V1 receptors. Nonetheless, some studies have also suggested additional vasodilatory effects at low concentrations in selected vascular beds, including coronary, pulmonary, and cerebral arteries. Circulating AVP, acting via specific V1 receptors in the area postrema, modulates central cardiovascular regulation by augmenting the baroreflex inhibition of efferent sympathetic nerve activity, and therefore counterbalances the caused increase in peripheral resistance. Moreover, there is growing evidence for the existence of AVP receptors located on the presynaptic terminals of central sympathetic efferent nerves in the spinal cord, the stimulation of which may decrease sympathetic excitability.

For more than 25years vasopressin indications were restricted to treating polyuria in patients with diabetes insipidus, reducing blood loss in patients with gastrointestinal bleeding and increasing the mobility of the gastrointestinal system. It was only in the 1990s that it was first used for its potent vasopressor effects in patients with cardiac arrest, ${ }^{2}$ septic shock, ${ }^{3}$ drug intoxication ${ }^{4}$ and for surgery of carcinoid tumors. ${ }^{5}$

Since then there are several studies that have demonstrated the augmented vasoconstrictor action of vasopressin, which can persist for up to $2 \mathrm{~h}$, in patients with hypotension not responding to high-dose norepinephrine, dopamine and fluid resuscitation. ${ }^{5,6}$ Another important advantage of vasopressin is the less prominent vasoconstriction in the coronary and cerebral circulation compared to the rest of the circulation. In addition to the double beneficial action of vasopressin in the myocardium and brain, there is a protective action to the kidneys as well. The increased urine output is a remarkable result of infused vasopressin that, according to several studies, is caused by the increased MAP which, consequently, improves the glomerular filtration rate.

The first reports for AVP use in cardiac surgery, by Argenziano et al. ${ }^{8} \&$ Masetti et al., ${ }^{9}$ showed promising results referring to its use for separation from cardiopulmonary bypass. More recently, Elgebaly et al. ${ }^{10}$ \& Yimin et al. ${ }^{11}$ suggested the beneficial role of vasopressin in supporting circulation after heart operations against various
Volume I Issue I - 2014

\author{
Stavros Siminelakis, Thalia Syminelaki \\ Department of Medicine, University of loannina, Greece
}

Correspondence: Stavros Siminelakis, Assoc. Prof. of Cardiac Surgery, loannina University, School of Health Sciences, Department of Medicine, Division of Cardiac Surgery, loannina, St. Niarchou Ave. 45 500, Greece, Email ssiminel@yahoo.com

Received: August 21, 2014 | Published: August 22, 2014

conditions, such as low ejection fraction, extended vasodilatation from ACE inhibitors and long bypass time for complex operations.

Patients undergoing $\mathrm{CABG}$ surgery need to maintain a slower heart rate to reduce myocardial oxygen consumption and facilitate their recovery. Cardiopulmonary bypass typically increases vasopressin plasma concentrations. Some patients however develop post-bypass hypotension as part of a systemic inflammatory response and are in need of vasopressors. In these patients, low AVP plasma concentrations have been found. Risk factors for post-bypass shock with inappropriately low AVP plasma concentrations are low ejection fraction and use of angiotensin-converting enzyme inhibitors. Catecholamines could be used to increase blood pressure on one hand, but on the other they would also increase heart rate and oxygen demands, pulmonary vascular resistance (PVR) and pulmonary artery pressure (PAP). On the contrary there is no evidence to support that the use of low doses of vasopressin $(0.04 \mathrm{U} / \mathrm{min})$ increased PVR or PAP. The observed vasodilatory effect of vasopressin in the pulmonary vasculature, may be attributed to a release of NO by the pulmonary capillaries' endothelium. Because of the above described action, vasopressin (AVP) has been successfully used in cardiac surgical patients with preoperative pulmonary hypertension. Additionally, Vasopressin infusion tends to improve myocardial performance by increasing the intramyocardial calcium concentrations and producing coronary artery vasodilatation in combination with the increase in myocardial blood flow due to increased systemic perfusion pressure. ${ }^{7}$

Sixty years have passed since vasopressin synthetic preparation and more than 15years since the first proof of its advantages in heart patients. However there is still great hesitation regardless the nonstop growing evidence. It is high time to accept its tremendously beneficial role in cardiac surgery.

\section{Acknowledgements}

None.

\section{Conflict of interest}

The author declares no conflict of interest. 


\section{References}

1. Du Vigneaud V, Gash DT, Katsoyannis PG. A synthetic preparation possessing biological properties associated with argininevasopressin. $J$ Am Chem Soc. 1954;76(18):4751-4752.

2. Lindner KH, Dirks B, Strohmenger HU, et al. Randomised comparison of epinephrine and vasopressin in patients with out-of hospital ventricular fibrillation. Lancet. 1997;349(9051):535-537.

3. Landry DW, Levin HR, Gallant EM, et al. Vasopressin pressor hypersensitivity in vasodilatory septic shock. Crit Care Med. 1997;25(8):1279-1282.

4. Leone M, Charvet A, Delmas A, et al. Terlipressin: A new therapeutic for calcium-channel blocker overdose. J Crit Care. 2005;20(1):114-115.

5. Veall GR, Peacocdk JE, Bax ND, et al. Review of the anaesthetic management of 21 patients undergoing laparotomy for carcinoid syndrome. Br J Anaesth. 1994;72(3):335-341.

6. Wenzel V, Krismer AC, Arntz HR, et al. A Comparison of Vasopressin and epinephrine for out-of-hospital cardiopulmonary resuscitation. $N$ Engl $J$ Med. 2004;350(2):105-13.
7. Papadopoulos G, Sintou E, Siminelakis S, et al. Perioperative infusion of low dose of vasopressin for prevention and management of vasodilatory vasoplegic syndrome in patients undergoing coronary artery bypass grafting-A double-blind randomized study. $J$ Cardiothorac Surg. 2010;5:17.

8. Argenziano M, Chen JM, Choudhri AF, et al. Management of vasodilatory shock after cardiac surgery: identification of predisposing factors and use of a novel pressor agent. J Thorac Cardiovasc Surg. 1998;116(6):973-980.

9. Masetti P, Murphy SF, Kouchoukos NT. Vasopressin therapy for vasoplegic syndrome following cardiopulmonary bypass. J Card Surg. 2002;17(6):485-489.

10. Elgebaly AS, Sabry M. Infusion of low-dose vasopressin improves left ventricular function during separation from cardiopulmonary bypass: A double-blind randomized study. Ann Card Anaesth. 2012;15(2):128-133.

11. Yimin H, Xiaoyu L, Yuping H, et al. The effect of vasopressin on the hemodynamics in CABG patients. J Cardiothorac Surg. 2013;8:49. 